\title{
miR-20a-5p inhibits endometrial cancer progression by targeting janus kinase 1
}

\author{
YING HE $^{1}$, HUI MA ${ }^{1}$, JING WANG ${ }^{1}$, YANHUA KANG ${ }^{1}$ and QIANLONG XUE ${ }^{2}$ \\ ${ }^{1}$ Department of Gynaecology and ${ }^{2}$ Emergency Department, \\ The First Affiliated Hospital of Hebei North University, Zhangjiakou, Hebei 075000, P.R. China
}

Received July 28, 2020; Accepted December 21, 2020

DOI: $10.3892 / \mathrm{ol} .2021 .12688$

\begin{abstract}
Endometrial cancer (EC) is a multi-factorial disease of which pathogenesis has not been fully elucidated. The function and underlying mechanism of microRNA-20a-5p (miR-20a-5p) in EC remain poorly understood. The present study aimed to analyze the association between miR-20a-5p expression and the clinicopathological characteristics of patients with EC. Whether miR-20a-5p could inhibit EC progression by targeting janus kinase 1 (Jak1) was subsequently investigated. To do so, human EC tissues and paracancerous tissues were collected from 47 patients with EC. miR-20a-5p and Jak1 mRNA and protein expression was determined by reverse transcription quantitative PCR and western blotting, respectively. Cell proliferation, invasive ability and adhesion were investigated by MTT, Matrigel invasion and cell adhesion assays, respectively. Dual luciferase reporter assay was used to verify whether miR-20a-5p could directly target Jak1. The results demonstrated that miR-20a-5p was downregulated and that Jak1 was upregulated in EC tissues compared with paracancerous tissues. In addition, miR-20a-5p expression and Jak1 expression level were negatively correlated in EC tissues. miR-20a-5p expression was also significantly associated with the depth of myometrial invasion, FIGO stage, histologic grade and lymph node metastasis in patients with EC. Furthermore, Jak1 was identified as a new direct target of miR-20a-5p, and Jak1 overexpression was demonstrated to reverse the effects of miR-20a-5p-mimic on EC cell proliferation, invasive ability and adhesion. Taken together, the results from this study revealed for the first time that miR-20a-5p expression was significantly associated with the clinicopathological characteristics of patients with EC. These findings suggested that miR-20a-5p may act as a tumor suppressor in EC, in part through decreasing Jak1 expression. miR-20a-5p and Jak1 may therefore serve as potential therapeutic targets in EC.
\end{abstract}

Correspondence to: Dr Qianlong Xue, Emergency Department, The First Affiliated Hospital of Hebei North University, 12 Changqing Road, Zhangjiakou, Hebei 075000, P.R. China E-mail: ldfwaike@163.com

Key words: miR-20a-5p, janus kinase 1, endometrial cancer

\section{Introduction}

Endometrial cancer (EC) is the most common gynaecological cancer in developed countries, and the incidence of EC is increasing rapidly worldwide $(1,2)$. Over 189,000 cases of endometrial cancer are diagnosed worldwide per year and $\sim 45,000$ mortality cases $(3,4)$. EC is a multi-factorial disease of which pathogenesis has not been fully elucidated. Most cases of EC are diagnosed at an early-stage and have a good prognosis after surgery alone; however, the 5-year survival rate is only $17 \%$ for patients with distant metastatic disease $(5,6)$. It is therefore crucial to understand the underlying mechanisms of EC metastasis in order to develop effective strategies for EC diagnosis and therapy.

MicroRNAs (miRs) are a class of short non-coding RNAs that regulate gene expression at the post-transcriptional level by binding to the 3' untranslated region (3'UTR) of target mRNA (7). Abnormal expression of miRNAs has been found in various types of tumor and is frequently associated with numerous aspects of tumor progression, including proliferation, differentiation, invasion, migration, apoptosis and senescence (8). Emerging evidence has revealed that several miRNAs are dysregulated in EC (9-11) and can act as either potent oncogenes or tumor suppressor genes (12-14). For example, miR-23a and miR-135a have been demonstrated to inhibit EC development $(12,14)$. Conversely, miR-29b can inhibit the proliferation and decrease the migratory and invasive abilities of EC cells (13). miR-20a-5p is a member of the miR-17-92 cluster, which plays a complex role in tumorigenesis (15). Dysregulation of miR-20a-5p has been observed in various cancers, including colorectal cancer, cervical cancer, ovarian cancer and hepatocellular carcinoma (16). Ramón et al (17) reported that miR-20a-5p is significantly downregulated in cancerous endometrium compared with control endometrium. Furthermore, a negative correlation between vascular endothelial growth factor A protein expression and miR-20a expression is observed in EC specimens (17). However, the function and underlying mechanism of miR-20a-5p in EC remain poorly understood.

Janus kinase 1 (Jak1) is a member of a class of protein-tyrosine kinases which are involved in autoimmune diseases and malignancies $(18,19)$. Jak1 phosphorylates the proteins named signal transducers and activators of transcription in response to interferon (20) and serves a critical role in cancer progression.

The present study aimed to examine the expression of miR-20a-5p in human EC tissues and to determine the association 
between miR-20a-5p expression and the clinicopathological characteristics of patients with EC. The effects of miR-20a-5p on cell proliferation, invasive ability and adhesion were investigated. Whether miR-20a-5p could inhibit EC progression by targeting janus kinase 1 (Jak1) was also evaluated. The findings from this study might provide a better understanding of EC pathogenesis.

\section{Materials and methods}

Tissue collection. The present study was approved by the Ethics Committee of The First Affiliated Hospital of Hebei North University (Zhangjiakou, Hebei, China). All patients provided written informed consent in compliance with the code of ethics of the World Medical Association (Declaration of Helsinki). Human EC tissues and paracancerous tissues were collected from 47 patients with EC who underwent surgical resection. None of the patients had received chemotherapy or radiotherapy prior to surgery. The tissue samples were immediately frozen in liquid nitrogen.

Cell culture and transfection. The normal human endometrial stromal cell line hESC (cat. no. BNCC340262) and the EC cell lines Ishikawa, KLE, HHUA and RL95-2 were purchased from BeNa Culture Collection. All cells were cultured in Dulbecco's modified Eagle's medium/F12 (Invitrogen; Thermo Fisher Scientific, Inc.) supplemented with 10\% FBS (Invitrogen; Thermo Fisher Scientific, Inc.). HEK293 cells were purchased from the American Type Culture Collection and cultured in RPMI Medium 1640 (Invitrogen; Thermo Fisher Scientific, Inc.) supplemented with $10 \% \mathrm{FBS}$. Cells were placed at $37^{\circ} \mathrm{C}$ in a humidified incubator containing $5 \% \mathrm{CO}_{2}$. Ishikawa cells were transfected with $2 \mu \mathrm{M}$ miR-negative control (NC), $2 \mu \mathrm{M}$ miR-20a-5p-mimic, $2 \mu \mathrm{M}$ miR-20a-5p-inhibitor, $4 \mu \mathrm{g}$ pcDNA3.1 or $4 \mu \mathrm{g}$ Jak1-pcDNA3.1 (Shanghai GenePharma Co., Ltd.) using Lipofectamine 2000 (Invitrogen; Thermo Fisher Scientific, Inc.) according to the manufacturers' instructions. After $48 \mathrm{~h}$, cells were observed under a fluorescence microscope and the transfection efficiency was $>80 \%$ (Fig. S1).

Reverse transcription-quantitative $(R T-q) P C R$. miRNAs were isolated from tissues or cultured cells using mirVanaTM miR isolation kit (Ambion; Thermo Fisher Scientific, Inc.). Total RNA was isolated using TRIzol reagent (Invitrogen; Thermo Fisher Scientific, Inc.). cDNA was synthesized from 5 ng of total RNA using the First Strand cDNA Synthesis kit (Fermentas; Thermo Fisher Scientific, Inc.) according to the manufacturers' instructions. The sequences of primers were as follows: Jak1, forward 5'-AGCGATGTCCTTACCACACC-3', reverse 5'-CCTCAACACACTCAGGAGCA-3'; GAPDH, forward 5'-TCAACGACCACTTTGTCAAGCTCA-3', reverse 5'-GCTGGTGGTCCAGGGGTCTTACT-3'; miR-20a-5p, forward 5'-TAAAGTGCTTATAGTGCAGGTAG-3', reverse 5'-TGGTGTCGTGGAGTCG-3'; and U6, forward 5'-CTCGCT TCGGCAGCACA-3' and reverse 5'-AACGCTTCACGAATT TGCGT-3'. Amplification and detection were performed with a SYBR-Green PCR kit (Applied Biosystems; Thermo Fisher Scientific, Inc.) on the ABI PRISM 7700 Sequence Detection System (Applied Biosystems; Thermo Fisher Scientific, Inc.). The thermocycling conditions were as follows: $95^{\circ} \mathrm{C}$ for $4 \mathrm{~min}$, followed by 40 cycles of $95^{\circ} \mathrm{C}$ for $30 \mathrm{sec}, 59^{\circ} \mathrm{C}$ for $30 \mathrm{sec}$ and $72^{\circ} \mathrm{C}$ for $1 \mathrm{~min}$ with a final extension at $72^{\circ} \mathrm{C}$ for $5 \mathrm{~min}$. The relative expression levels were normalized to endogenous controls U6 and GAPDH and were expressed as $2^{-\Delta \Delta \mathrm{Cq}}(21)$.

Western blotting. Tissues and cells were collected and lysed using RIPA buffer (Beyotime Institute of Biotechnology) at $4^{\circ} \mathrm{C}$. Protein concentration was determined using the BCA Protein Assay kit (Beyotime Institute of Biotechnology). Proteins $(40 \mu \mathrm{g})$ were separated by $10 \%$ SDS-PAGE and transferred onto PVDF membranes (EMD Millipore). Subsequently, membranes were blocked with $5 \%$ skimmed milk at $4^{\circ} \mathrm{C}$ overnight. After washing in Tris-buffered saline-Tween-20 (0.05\%) solution, membranes were incubated with mouse monoclonal primary antibodies against Jak1 (1:400; cat. no. sc376996; Santa Cruz Biotechnology, Inc.) and GAPDH (1:1,000; cat. no. sc365062; Santa Cruz Biotechnology, Inc.) at $4^{\circ} \mathrm{C}$ overnight. Membranes were then incubated with IgG-horseradish peroxidase-conjugated secondary antibody (1:5,000; cat. no. sc2005; Santa Cruz Biotechnology, Inc.) at $37^{\circ} \mathrm{C}$ for $1 \mathrm{~h}$. Pierce SuperSignal West Pico Chemiluminescent Substrate (Pierce Biotechnology, Inc.) was used to detect the signal on the membrane. The data were analyzed via densitometry using ImageJ software (version 1.8.0; National Institutes of Health) and normalized to expression of the internal control GAPDH.

Dual luciferase reporter assay. Plasmid constructs carrying wild type or mutant Jak1 3'UTR in the psiCHECK vector were cotransfected with miR-20a-5p mimic or miR NC into HEK293 cells using Lipofectamine 2000. miR-20a-5p mimic and miR NC were synthesized by Shanghai GenePharma Co., Ltd. and the sequences were as follows: miR-20a-5p mimic, sense, 5'-UAAAGUGCUUAUAGUGCAGGUAG-3'; miR-20a-5p mimic, antisense, 5'-ACCUGCACUAUAAGCACUUUAUU-3'. miR NC, 5'-UUGUACUACACAAAAGUACUG-3'. After 48 h, the luciferase activity was measured using the Dual-Luciferase Reporter 1000 System (Promega Corporation). Renilla luciferase activity was normalized to firefly luciferase activity to control transfection efficiency.

MTT assay. Cell proliferation was determined using a MTT Assay Kit from Abcam according to the manufacturers' instructions. Briefly, cells at the density of $1 \times 10^{4} /$ well were cultured in 96-well plates for 24, 48, 72 and $96 \mathrm{~h}$ and were incubated with $10 \mu \mathrm{l}$ of MTT reagent for $3 \mathrm{~h}$ at $37^{\circ} \mathrm{C}$. Subsequently, MTT solvent was added to dissolve purple formazan crystals and cells were further incubated at $37^{\circ} \mathrm{C}$ for $15 \mathrm{~min}$. Absorbance was read at $570 \mathrm{~nm}$ using a microplate reader (Bio-Rad Laboratories, Inc.).

Cell invasionassay. Transwell inserts (Corning) were precoated with Matrigel (1:20; Corning) $37^{\circ} \mathrm{C}$ for $30 \mathrm{~min}$ before seeding the cells. At $48 \mathrm{~h}$ post-transfection, cells were collected with serum-free media and seeded into the upper chamber at a final concentration of $5 \times 10^{4}$ cells $/ \mathrm{ml}$ whereas medium containing $10 \%$ FBS was added into the lower chamber. After incubation at $37^{\circ} \mathrm{C}$ for $8 \mathrm{~h}$, the non-invasive cells in the upper chamber were removed gently using cotton swabs. The cells that have invaded the bottom of the membranes were fixed with ethanol, stained with hematoxylin. Cells were observed under an inverted light microscope (CKX31, Olympus Corporation; magnification, $x 400)$. The number of invaded cells was 
Table I. The association between miR-20a-5p expression and clinicopathologic features of EC patients.

\begin{tabular}{lcc}
\hline Clinicopathologic features & Cases, $\mathrm{n}=47$ & miR-20a-5p expression \\
\hline Age, years & & \\
$\quad$ P-value \\
$>55$ & 26 & $0.448 \pm 0.08$ \\
$>55$ & & $0.413 \pm 0.11$ \\
Depth of myometrial invasion & 35 & $0.413 \pm 0.097$ \\
$<1 / 2$ & 12 & $0.490 \pm 0.067$ \\
$\geq 1 / 2$ & & \\
FIGO stage & 34 & $0.414 \pm 0.097$ \\
I+II & 13 & $0.481 \pm 0.076$ \\
III+IV & & \\
Histologic grade & 30 & $0.404 \pm 0.098$ \\
G1 & 7 & $0.430 \pm 0.043$ \\
G2 & 10 & $0.518 \pm 0.065$ \\
G3 & & \\
Lymph node metastasis & 8 & 0.015 \\
Yes & 39 & $0.422 \pm 0.100$ \\
No & & 0.003 \\
\hline
\end{tabular}

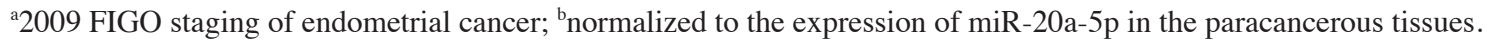

quantified by counting five randomly chosen microscopic fields.

Fibronectin adhesion assay. At $48 \mathrm{~h}$ post-transfection, cells were seeded at the density of $5 \times 10^{4}$ cells per well into 96-well plates that were precoated with $1 \%$ human plasma fibronectin-purified protein (EMD Millipore). After incubation at $37^{\circ} \mathrm{C}$ for $2 \mathrm{~h}$, cells were washed with PBS three times and fixed with $3.7 \%$ formaldehyde at room temperature for 40 min. Cells were stained with $0.1 \%$ crystal violet solution at room temperature for $30 \mathrm{~min}$ and the crystal violet was then solubilized in $10 \%$ acetic acid solution. The absorbance was determined at $570 \mathrm{~nm}$ using a microplate reader (Bio-Rad).

Statistical analysis. Statistical analysis was performed using SPSS 19.0 (IBM Corp.). The data were presented as the means \pm standard deviation and analyzed by Student's t-test or ANOVA followed by Bonferroni's post hoc test. $\mathrm{P}<0.05$ was considered to indicate a statistically significant difference.

\section{Results}

miR-20a-5p is downregulated in EC tissues and associated with the clinicopathological characteristics of patients with $E C$. Expression of miR-20a-5p in EC and paracancerous tissues was examined by RT-qPCR. As presented in Fig. 1, miR-20a-5p was significantly downregulated in EC tissues compared with paracancerous tissues $(\mathrm{P}<0.01)$. Furthermore, miR-20a-5p expression was found to be significantly associated with the depth of myometrial invasion, FIGO stage, histologic grade and lymph node metastasis in patients with EC (Table I).

miR-20a-5p inhibits cell viability and invasive ability, and stimulates cell adhesion. Expression of miR-20a-5p in endometrial

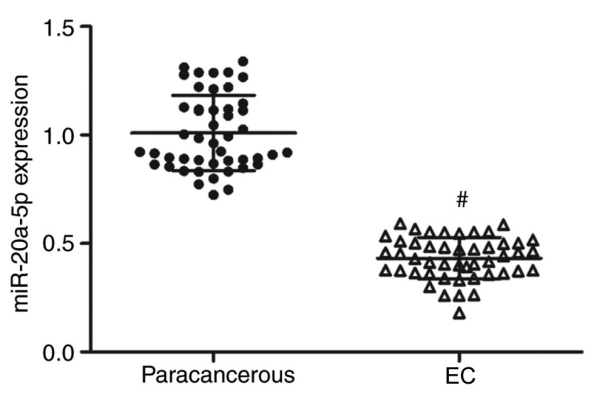

Figure 1. miR-20a-5p was downregulated in human EC tissues. ${ }^{\#} \mathrm{P}<0.01$ vs. paracancerous tissue. miR, microRNA; EC, endometrial cancer.

stromal cell line hESC and EC derived cell lines Ishikawa, KLE, RL95-2 and HHUA was examined by RT-qPCR. As presented in Fig. 2A, miR-20a-5p expression was significantly decreased in EC derived cells compared with hESC cells $(\mathrm{P}<0.01)$. To investigate the effect of miR-20a-5p on cell proliferation, invasive ability and adhesion, Ishikawa cell line, which exhibited the lowest miR-20a-5p level, was chosen for subsequent gain-of-function and loss-of-function experiments. miR NC, miR-20a-5p mimic and miR-20a-5p inhibitor were transfected into Ishikawa cells. As demonstrated in Fig. 2B, miR-20a-5p expression was significantly increased in mimic group and decreased in inhibitor group compared with NC group $(\mathrm{P}<0.01)$. Furthermore, Ishikawa cells transfected with miR-20a-5p-mimic showed decreased proliferation $(\mathrm{P}<0.05)$ and invasion ability $(\mathrm{P}<0.05)$, and increased adhesion ability compared with $\mathrm{NC}$ group $(\mathrm{P}<0.05)$. Ishikawa cells transfected with miR-20a-5p-inhibitor showed the opposite results (Fig. 2C-E).

Jakl is upregulated and associated with miR-20a-5p expression in EC tissues. Jak1 mRNA and protein expression in EC and 
A

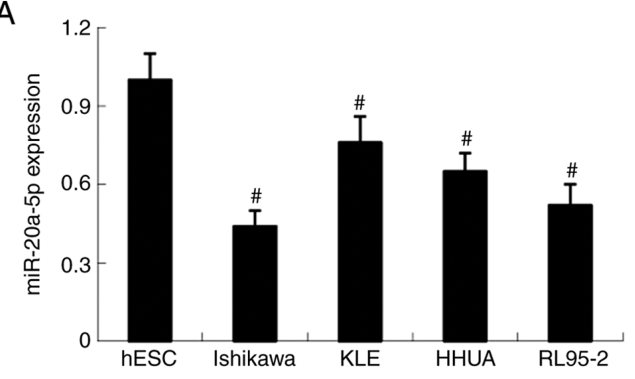

B

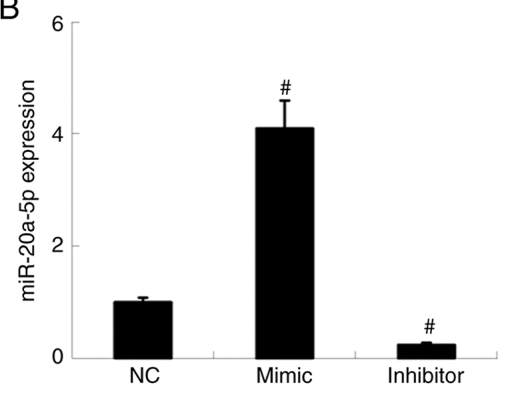

C

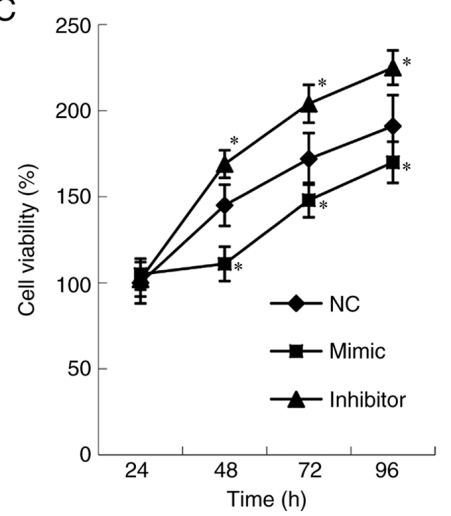

$\mathrm{E}$
D

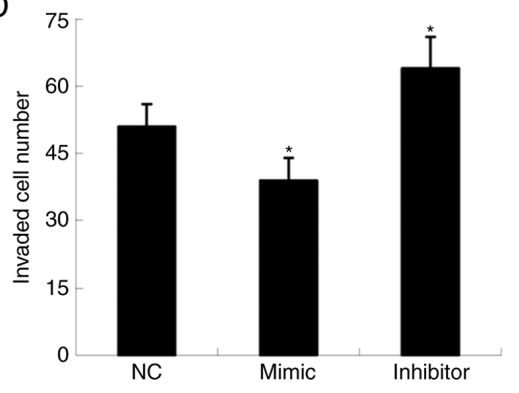

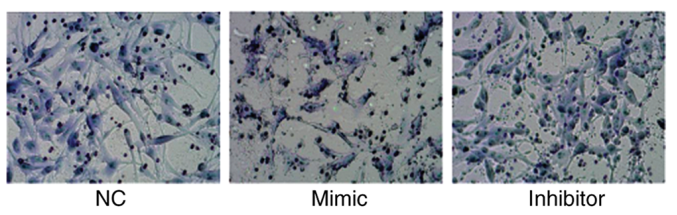

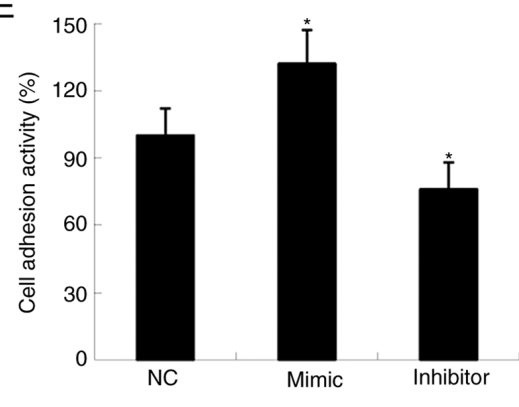

Figure 2. miR-20a-5p inhibited cell proliferation and invasive ability, and stimulated cell adhesion. (A) miR-20a-5p was significantly downregulated in the EC derived cell lines Ishikawa, KLE, RL95-2 and HHUA compared with endometrial stromal cell line hESC. (B) Expression of miR-20a-5p in Ishikawa cells following transfection with miR-20a-5p-mimic or inhibitor. Effects of miR-20a-5p on (C) cell proliferation, (D) cell invasive ability (magnification, $x 400)$ and (E) cell adhesion. ${ }^{*} \mathrm{P}<0.05$ and ${ }^{*} \mathrm{P}<0.01$. miR, microRNA; EC, endometrial cancer; NC, negative control.
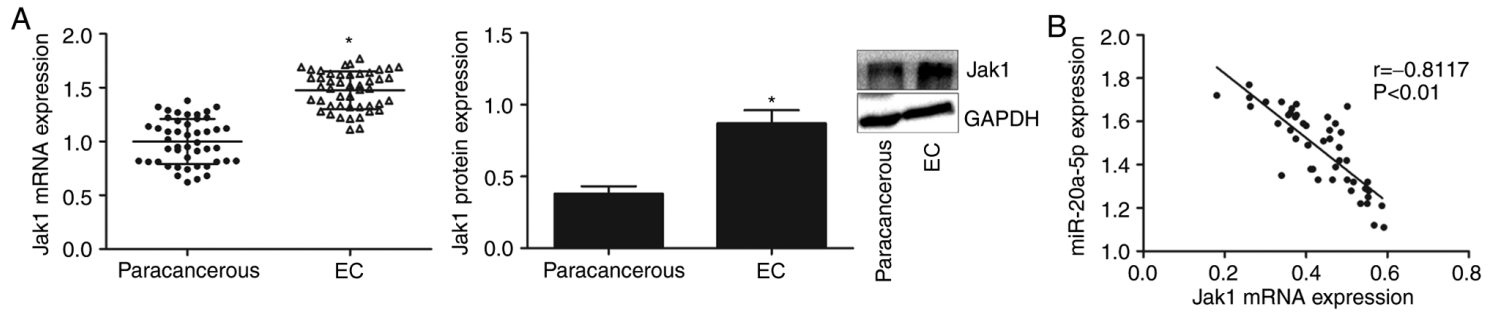

Figure 3. Expression of Jak1 in human EC tissues. (A) Jak1 was upregulated in human EC tissues. (B) Jak1 mRNA expression was negatively correlated with miR-20a-5p expression in human EC tissues. "P<0.05. miR, microRNA; EC, endometrial cancer; Jak, janus kinase 1.

paracancerous tissues was examined by RT-qPCR and western blotting, respectively. As presented in Fig. 3A, the mRNA and protein expression of Jak1 was significantly increased in EC tissues compared with paracancerous tissues $(\mathrm{P}<0.05)$. Furthermore, Jak1 mRNA expression was negatively correlated with miR-20a-5p expression in EC tissues ( $\mathrm{P}<0.01$; Fig. 3B).

miR-20a-5p directly targets Jak1. To verify whether miR-20a-5p could directly target Jak1, Jak1 3'UTR reporter assay was performed in HEK293 cells. As seen in Fig. 4A, the luciferase activity of wild type Jak1 3'UTR was significantly decreased in cells transfected with miR-20a-5p-mimic compared with cells transfected with miR-NC $(\mathrm{P}<0.01)$; however, no change was observed in the mutant Jak1 3'UTR. Furthermore, results from RT-qPCR and western blotting demonstrated that the mRNA and protein expression of Jak1 was significantly decreased in Ishikawa cells transfected with miR-20a-5p-mimic but increased in cells transfected with 


\section{A}

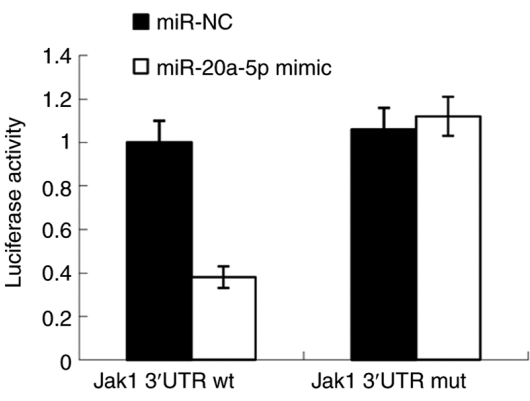

Jak1 3'UTR wt 5' guggccaCUCUAUGCACUUUg 3'

miR-20a-5p 3' gauggacGUGAUAUUUCGUGAAAu $5^{\prime}$

Jak1 3'UTR mut $3^{\prime}$ gaggccaCUCUAUAUCGUGAAAg 3'

B
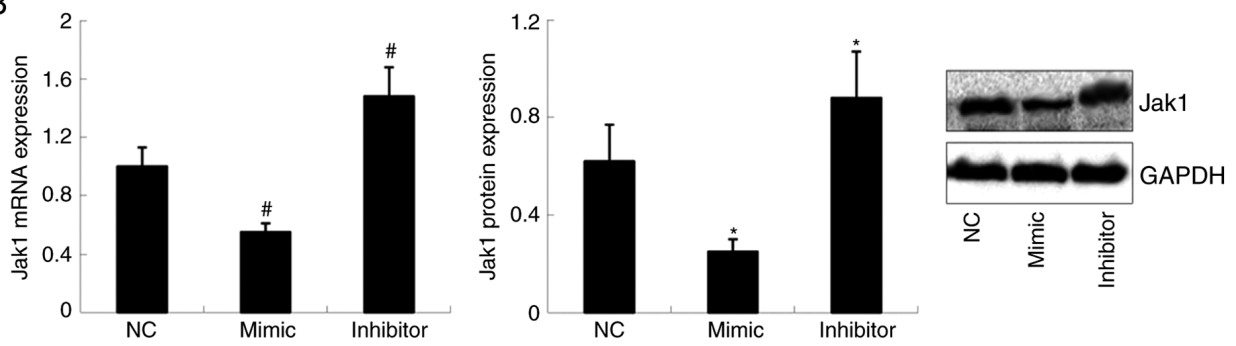

Figure 4. miR-20a-5p directly targeted Jak1. (A) Luciferase activity of wt-Jak1 3'UTR was significantly decreased in cells transfected with miR-20a-5p-mimic. (B) Effect of miR-20a-5p on Jak1 mRNA and protein expression. ${ }^{*} \mathrm{P}<0.05$ and ${ }^{~} \mathrm{P}<0.01$. miR, microRNA; EC, endometrial cancer; Jak, janus kinase 1; wt, wild-type; mut, mutant; NC, negative control.
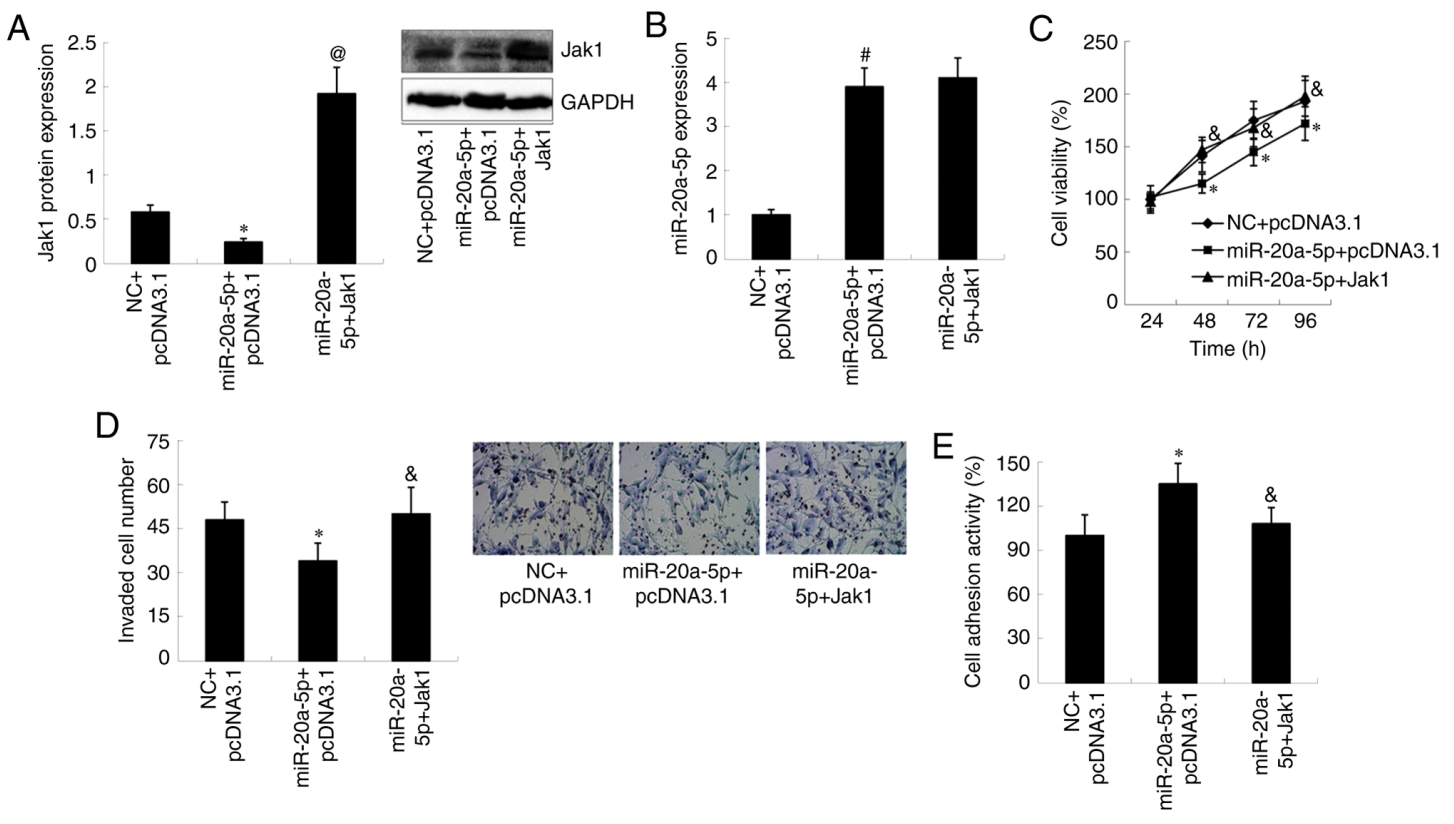

Figure 5. Jak1 reversed the effects of miR-20a-5p on cell viability, cell invasion and adhesion. Expression of (A) Jak1 protein and (B) miR-20a-5p in Ishikawa cells following transfection with miR-20a-5p-mimic and Jak1-pcDNA3.1. Jak1 overexpression abolished the effects of miR-20a-5p-mimic on (C) cell proliferation, (D) cell invasive ability (magnification, $\mathrm{x} 400$ ) and (E) cell adhesion. $\mathrm{P}<0.05$ and ${ }^{*} \mathrm{P}<0.01$ vs. $\mathrm{NC}+\mathrm{pc} \mathrm{DNA} 3.1$ group; ${ }^{\circledR} \mathrm{P}<0.05$ and ${ }^{\circledR} \mathrm{P}<0.01$ vs. miR-20a-5p + pc DNA3.1 group. miR, microRNA; EC, endometrial cancer; Jak, janus kinase 1; wt, wild-type; mut, mutant; NC, negative control.

miR-20a-5p-inhibitor $(\mathrm{P}<0.01$ for mRNA expression; $\mathrm{P}<0.05$ for protein expression; Fig. 4B).

Jakl overexpression reverses the effects of miR-20a-5p on cell proliferation, invasive ability and adhesion. Jak1-pcDNA3.1 and the empty vector pcDNA3.1 were transfected into Ishikawa cells. The results demonstrated that Jak1 mRNA and protein expression was significantly increased in the Jak1-pcDNA3.1 group compared with pcDNA3.1 group $(\mathrm{P}<0.01$ for mRNA, $\mathrm{P}<0.05$ for protein; Fig. $\mathrm{S} 2)$. To further investigate whether Jak1 was involved in mediating the effects of miR-20a-5p on cell proliferation, invasive ability and adhesion, Jak1-pcDNA3.1 was transfected into Ishikawa cells in the presence of miR-20a-5p mimic. The results demonstrated that Jak1 protein expression was significantly increased in cells transfected with the miR-20a-5p mimic and Jak1-pcDNA3.1 compared with cells transfected with miR-20a-5p-mimic only $(\mathrm{P}<0.01)$; however, the increased expression of miR-20a-5p in miR-20a-5p-mimic-transfected cells was not affected by Jak1-pcDNA3.1 transfection (Fig. 5A and B). Furthermore, 
the inhibitory effect of miR-20a-5p-mimic on cell proliferation and invasive ability, and the promotive effect of miR-20a-5p-mimic on cell adhesion were reversed by transfection with Jak1-pcDNA3.1 (P<0.05; Fig. 5C-E).

\section{Discussion}

Alteration in miR-20a-5p expression patterns is associated with endometrial growth, differentiation and carcinogenesis of the endometrium (22-24). Previous studies reported that miR-20a-5p is significantly decreased in the plasma and serum of patients with endometriosis, and that it serves important roles in the pathogenesis of endometriosis $(22,23)$. Conversely, miR-20a-5p expression was found to be upregulated in endometriotic stromal cells (24). In addition, in vitro application of hypoxia results in downregulation of miR-20a-5p in Ishikawa cells (25). In the present study, downregulation of miR-20a-5p was observed in EC tissues and cell lines compared with paracancerous tissues and endometrial stromal cells, respectively. Furthermore, miR-20a-5p expression was significantly associated with the depth of myometrial invasion, FIGO stage, histologic grade and lymph node metastasis in patients with EC. Patients with lower miR-20a-5p expression exhibited lower FIGO stage and histologic grade, as well as less myometrial invasion and lymph node metastasis.

miR-20a-5p serves various roles according to the type of cancer. Previous studies have demonstrated that miR-20a-5p can induce radioresistance in hepatocellular carcinoma and nasopharyngeal cancer cells $(26,27)$. Zhao et al (28) reported that miR-20a-5p can inhibit cell proliferation, mobility and invasiveness, and facilitate apoptosis in breast cancer. However, contrasting report indicated that miR-20a-5p promotes invasion and metastasis, and induces epithelial-mesenchymal transition of colorectal cancer cells (29). In the present study, miR-20a-5p was demonstrated to inhibit cell proliferation and cell invasive ability, as well as to induce cell adhesion ability. These findings were in agreement with a previous study reporting the suppressor role of miR-20a-5p in EC cell lines (30).

Numerous target genes of miR-20a-5p have been identified in previous studies, including cyclin D1, E2F transcription factor 3 , interleukin- 8 and dual specificity phosphatase $2(16,31)$. In the present study, miR-20a-5p expression and Jak1 expression levels were negatively correlated in EC tissues. Furthermore, Jak1 was demonstrated to be a direct target of miR-20a-5p following dual luciferase reporter assay. A previous study has reported that activated Jak1 might contribute to carcinogenesis in leukemias, lymphomas and myeloproliferative neoplasms (32). Sexl et al (33) reported that Jak1-deficient cells are more tumorigenic than wild-type cells. Jak1 can also act as either an oncogene or a tumor suppressor under certain conditions (34). The present study demonstrated that miR-20a-5p could decrease Jak1 expression in EC cells, and that Jak1 overexpression could reverse the effects of miR-20a-5p-mimic on EC cell proliferation, invasive ability and adhesion. These results supported the notion that Jak1 could contribute to EC progression $(35,36)$ and suggested that miR-20a-5p may play a tumor suppressive role in EC partly by decreasing Jak1 expression.
In the present study, miR-20a-5p expression was detected in four EC derived cell lines, and the results demonstrated that all these EC cell lines had significantly decreased miR-20a-5p expression compared with normal human endometrial stromal cells. Since Ishikawa cell line showed the lowest miR-20a-5p expression, it was selected for subsequent experiments. The present study was however limited because the gain- and loss-of-function experiments were only performed in the Ishikawa cell line. Functional experiments performed in additional cell lines is therefore required.

In conclusion, to the best of our knowledge, the present study was the first to demonstrate that miR-20a-5p expression was significantly correlated with the depth of myometrial invasion, FIGO stage, histologic grade and lymph node metastasis in patients with EC. In addition, miR-20a-5p expression and Jak1 mRNA expression were negatively correlated in EC tissues. Jak1 was confirmed as a novel target of miR-20a-5p, and miR-20a-5p acted as a tumor suppressor in EC at least partly through decreasing Jak1 expression. This study provided new insights into the underlying mechanisms of EC progression, and the findings suggested that miR-20a-5p and Jak1 may serve as potential therapeutic targets in EC. Further investigation is required to confirm the effect of miR-20a-5p in animal models of EC and to determine additional target genes of miR-20a-5p.

\section{Acknowledgements}

Not applicable.

\section{Funding}

This study was funded by Key Project of Science and Technology Plan of Hebei Health Committee (grant no. 20212598).

\section{Availability of data and materials}

The data sets generated and analyzed during the present study are available from the corresponding author on reasonable request.

\section{Authors' contributions}

QX and YH conceived and designed the experiments, analyzed the data and prepared the manuscript. HM and JW conducted the experiments. YK contributed to data collection and analysis. All authors read and approved the final version.

\section{Ethics approval and consent to participate}

This study was approved by the Ethics Committee of The First Affiliated Hospital of Hebei North University (Zhangjiakou, Hebei, China).

\section{Patient consent for publication}

All patients provided written informed consent in compliance with the code of ethics of the World Medical Association (Declaration of Helsinki). 


\section{Competing interests}

The authors declare that they have no competing interests.

\section{References}

1. Braun MM, Overbeek-Wager EA and Grumbo RJ: Diagnosis and management of endometrial cancer. Am Fam Physician 93 468-474, 2016.

2. McAlpine JN, Temkin SM and Mackay HJ: Endometrial cancer: Not your grandmother's cancer. Cancer 122: 2787-2798, 2016.

3. Tsikouras P, Bouchlariotou S, Vrachnis N Dafopoulos A Galazios G, Csorba R and von Tempelhoff GF: Endometrial cancer: Molecular and therapeutic aspects. Eur J Obstet Gynecol Reprod Biol 169: 1-9, 2013

4. Jemal A, Bray F, Center MM, Ferlay J, Ward E and Forman D: Global cancer statistics. CA Cancer J Clin 61: 69-90, 2011.

5. Siegel RL, Miller KD and Jemal A: Cancer statistics, 2018. CA Cancer J Clin 68: 7-30, 2018

6. Colombo N, Creutzberg C, Amant F, Bosse T, González-Martín A Ledermann J, Marth C, Nout R, Querleu D, Mirza MR, et al: ESMO-ESGO-ESTRO consensus conference on endometrial cancer: Diagnosis, treatment and follow-up. Ann Oncol 27: $16-41,2016$.

7. Lu TX and Rothenberg ME: MicroRNA. J Allergy Clin Immunol 141: 1202-1207, 2018.

8. Mohr AM and Mott JL: Overview of microRNA biology. Semin Liver Dis 35: 3-11, 2015.

9. Hutt S, Tailor A, Ellis P, Michael A, Butler-Manuel S and Chatterjee $\mathrm{J}$ : The role of biomarkers in endometrial cancer and hyperplasia: A literature review. Acta Oncol 58: 342-352, 2019.

10. Stope MB, Koensgen D, Weimer J, Paditz M, Burchardt M, Bauerschlag D and Mustea A: The future therapy of endometrial cancer: microRNA's functionality, capability, and putative clinical application. Arch Gynecol Obstet 294: 889-895, 2016.

11. Rižner TL: Discovery of biomarkers for endometrial cancer: Current status and prospects. Expert Rev Mol Diagn 16: $1315-1336,2016$

12. Li HL, Sun JJ, Ma H, Liu SJ, Li N, Guo SJ, Shi Y, Xu YY, Qi ZY, Wang YQ, et al: MicroRNA-23a inhibits endometrial cancer cell development by targeting SIX1. Oncol Lett 18: 3792-3802, 2019.

13. Kong J, He X, Wang Y and Li J: Effect of microRNA-29b on proliferation, migration, and invasion of endometrial cancer cells. J Int Med Res 47: 3803-3817, 2019.

14. Wang J, Zhang L, Jiang W, Zhang R, Zhang B, Silayiding A and Duan X: MicroRNA-135a promotes proliferation, migration, invasion and induces chemoresistance of endometrial cancer cells. Eur J Obstet Gynecol Reprod Biol X 5: 100103, 2020.

15. Fuziwara CS and Kimura ET: Insights into Regulation of the miR-17-92 Cluster of miRNAs in Cancer. Front Med (Lausanne) 2: 64, 2015

16. Agrawal S, Tapmeier T, Rahmioglu N, Kirtley S, Zondervan K and Becker C: The miRNA Mirage: How close are we to finding a non-invasive diagnostic biomarker in endometriosis? A systematic review. Int J Mol Sci 19: 599, 2018

17. Ramón LA, Braza-Boïls A, Gilabert J, Chirivella M, España F, Estellés A and Gilabert-Estellés J: MicroRNAs related to angiogenesis are dysregulated in endometrioid endometrial cancer. Hum Reprod 27: 3036-3045, 2012.

18. Schwartz DM, Bonelli M, Gadina M and O'Shea JJ: Type I/II cytokines, JAKs, and new strategies for treating autoimmune diseases. Nat Rev Rheumatol 12: 25-36, 2016.

19. Kleppe M, Kwak M, Koppikar P, Riester M, Keller M, Bastian L, Hricik T, Bhagwat N, McKenney AS, Papalexi E, et al: JAK-STAT pathway activation in malignant and nonmalignant cells contributes to MPN pathogenesis and therapeutic response. Cancer Discov 5: 316-331, 2015.
20. Mitchell TJ and John S: Signal transducer and activator of transcription (STAT) signalling and T-cell lymphomas. Immunology 114: 301-312, 2005

21. Livak KJ and Schmittgen TD: Analysis of relative gene expression data using real-time quantitative PCR and the 2(-Delta Delta C(T)) method. Methods 25: 402-408, 2001.

22. Wang L, Huang W, Ren C, Zhao M, Jiang X, Fang X and Xia X: Analysis of serum microRNA profile by solexa sequencing in women with endometriosis. Reprod Sci 23: 1359-1370, 2016.

23. Jia SZ, Yang Y, Lang J, Sun P and Leng J: Plasma miR-17-5p, miR-20a and miR-22 are down-regulated in women with endometriosis. Hum Reprod 28: 322-330, 2013.

24. Lin SC, Wang CC, Wu MH, Yang SH, Li YH and Tsai SJ: Hypoxia-induced microRNA-20a expression increases ERK phosphorylation and angiogenic gene expression in endometriotic stromal cells. J Clin Endocrinol Metab 97: E1515-E1523, 2012.

25. Eismann J, Hirschfeld M, Erbes T, Rücker G, Jäger M, Ritter A, Weiss D, Gitsch G and Mayer S: Hypoxia- and acidosis-driven aberrations of secreted microRNAs in endometrial cancer in vitro. Oncol Rep 38: 993-1004, 2017.

26. Zhang Y, Zheng L, Ding Y, Li Q, Wang R, Liu T, Sun Q, Yang H, Peng S, Wang W and Chen L: miR-20a induces cell radioresistance by activating the PTEN/PI3K/Akt signaling pathway in hepatocellular carcinoma. Int J Radiat Oncol Biol Phys 92: 1132-1140, 2015.

27. Huang D, Bian G, Pan Y, Han X, Sun Y, Wang Y, Shen G, Cheng M, Fang $X$ and Hu S: miR-20a-5p promotes radio-resistance by targeting Rab27B in nasopharyngeal cancer cells. Cancer Cell Int 17: 32, 2017.

28. Zhao W, Geng D, Li S, Chen Z and Sun M: LncRNA HOTAIR influences cell growth, migration, invasion, and apoptosis via the miR-20a-5p/HMGA2 axis in breast cancer. Cancer Med 7: $842-855,2018$.

29. Cheng D, Zhao S, Tang H, Zhang D, Sun H, Yu F, Jiang W, Yue B, Wang J, Zhang M, et al: MicroRNA-20a-5p promotes colorectal cancer invasion and metastasis by downregulating Smad4. Oncotarget 7: 45199-45213, 2016.

30. Huang Y and Yang N: MicroRNA-20a-5p inhibits epithelial to mesenchymal transition and invasion of endometrial cancer cells by targeting STAT3. Int J Clin Exp Pathol 11: 5715-5724, 2018.

31. Chen LT and Jiang CY: MicroRNA expression profiles identify biomarker for differentiating the embolic stroke from thrombotic stroke. Biomed Res Int 2018: 4514178, 2018.

32. Roskoski R Jr: Janus kinase (JAK) inhibitors in the treatment of inflammatory and neoplastic diseases. Pharmacol Res 111: 784-803, 2016

33. Sexl V, Kovacic B, Piekorz R, Moriggl R, Stoiber D, Hoffmeyer A, Liebminger R, Kudlacek O, Weisz E, Rothammer K and Ihle JN: Jak1 deficiency leads to enhanced Abelson-induced B-cell tumor formation. Blood 101: 4937-4943, 2003.

34. Yeh YT, Ou-Yang F, Chen IF, Yang SF, Su JH, Hou MF and Yuan SS: Altered p-JAK1 expression is associated with estrogen receptor status in breast infiltrating ductal carcinoma. Oncol Rep 17: 35-39, 2007.

35. van der Zee M, Sacchetti A, Cansoy M, Joosten R, Teeuwssen M, Heijmans-Antonissen C, Ewing-Graham PC, Burger CW, Blok LJ and Fodde R: IL6/JAK1/STAT3 signaling blockade in endometrial cancer affects the ALDHhi/CD126+ $6^{+}$stem-like component and reduces tumor burden. Cancer Res 75: 3608-3622, 2015.

36. Ren Y, Zhang Y, Liu RZ, Fenstermacher DA, Wright KL, Teer JK and Wu J: JAK1 truncating mutations in gynecologic cancer define new role of cancer-associated protein tyrosine kinase aberrations. Sci Rep 3: 3042, 2013.

This work is licensed under a Creative Commons Attribution-NonCommercial-NoDerivatives 4.0 International (CC BY-NC-ND 4.0) License. 